\title{
Metabolic Disorders and Male Hypogonadotropic Hypogonadism
}

\section{Rosario Pivonello*, Davide Menafra, Enrico Riccio, Francesco Garifalos, Marco Mazzella, Cristina de Angelis and Annamaria Colao}

Dipartimento di Medicina Clinica e Chirurgia, Sezione di Endocrinologia, Centro di Andrologia, Medicina della Riproduzione e della Sessualità Maschile e Femminile (FERTISEXCARES), Università "Federico II" di Napoli, Naples, Italy

Several studies highlight that testosterone deficiency is associated with, and predicts, an increased risk of developing metabolic disorders, and, on the other hand, is highly prevalent in obesity, metabolic syndrome and type-2 diabetes mellitus. Models of gonadotropin releasing hormone deficiency, and androgen deprivation therapy in patients with prostate cancer, suggest that hypogonadotropic hypogonadism might contribute to the onset or worsening of metabolic conditions, by increasing visceral adiposity and insulin resistance. Nevertheless, in functional hypogonadism, as well as in late onset hypogonadism, the relationship between hypogonadotropic hypogonadism and metabolic disorders is bidirectional, and a vicious circle between the two components has been documented. The mechanisms underlying the crosstalk between testosterone deficiency and metabolic disorders include increased visceral adipose tissue and insulin resistance, leading to development of metabolic disorders, which in turn contribute to a further reduction of testosterone levels. The decrease in testosterone levels might be determined by insulin resistance-mediated and, possibly, pro-inflammatory cytokine-mediated decrease of sex hormone binding globulin, resulting in a temporary increased free testosterone available for aromatization to estradiol in visceral adipose tissue, followed by a subsequent decrease in free testosterone levels, due to the excess of visceral adipose tissue and aromatization; by a direct inhibitory effect of increased leptin levels on Leydig cells; and by a reduced gonadotropin secretion induced by estradiol, inflammatory mediators, leptin resistance, and insulin resistance, with the ultimate determination of a substantial hypogonadotropic hypogonadism. The majority of studies focusing on the effects of testosterone replacement therapy on metabolic profile reported a beneficial effect of testosterone on body weight, waist circumference, body mass index, body composition, cholesterol levels, and glycemic control. Consistently, several interventional studies demonstrated that correction of metabolic disorders, in particular with compounds displaying a greater impact on body weight and insulin resistance, improved testosterone levels. The aim of the current review is to provide a comprehensive overview on the relationship between hypogonadotropic hypogonadism and metabolism, by clarifying the independent role of testosterone deficiency in the pathogenesis of metabolic disorders, and by describing the relative role of testosterone deficiency and metabolic impairment, in the context of the bidirectional relationship between hypogonadism and metabolic diseases documented in functional hypogonadotropic hypogonadism. These aspects will be assessed by describing metabolic profile in men 
with hypogonadotropic hypogonadism, and androgenic status in men with metabolic disorders; afterwards, the reciprocal effects of testosterone replacement therapy and corrective interventions on metabolic derangements will be reported.

Keywords: hypogonadotropic hypogonadism, metabolic disorders, type-2 diabetes mellitus, obesity, metabolic syndrome, testosterone, body composition, insulin resistance

\section{INTRODUCTION}

Hypogonadism is a clinical condition characterized by an impairment of gonadal function; in men, the condition implies the presence of testosterone deficiency, with circulating testosterone levels below the normal range, often accompanied by an impairment of spermatogenesis, and the presence of a clinical syndrome mainly characterized by sexual dysfunction, generalized asthenia, reduction of testis volume, and gynecomastia, together with anemia and deterioration of muscle mass and strength and bone status (1). Moreover, hypogonadism is often associated with metabolic comorbidities, such as obesity, insulin resistance (IR), metabolic syndrome (MetS), and type-2 diabetes mellitus (T2-DM) (2).

Hypogonadism is classified as primary, if the underlying cause of the endocrine dysfunction is testicular failure, or central, if the underlying cause of the endocrine disorder relies on the hypothalamus-pituitary dysfunction. In primary hypogonadism, gonadotropins levels are generally increased, and the condition is defined hypergonadotropic hypogonadism (Hyper- $\mathrm{H}$ ), whereas in central hypogonadism, gonadotropins levels are decreased, and the condition is defined hypogonadotropic hypogonadism (Hypo-H) (1). Hypothalamic and pituitary non-functioning and functioning tumors, hyperprolactinemia, pituitary surgery and irradiation, cranial trauma causing stalk injury, infiltrative diseases, such as hemochromatosis, sarcoidosis, and histiocytosis $\mathrm{X}$, infectious pituitary lesions, acute systemic illness, medications including gonadotropin releasing hormone $(\mathrm{GnRH})$ agonists or antagonists, opioids, and glucocorticoids, eating disorders, excessive exercise, and abuse of alcohol or addictive drugs may determine an acquired form of Hypo-H (1). Conversely, congenital Hypo-H is a rare pathological condition associated with a congenital deficiency of hypothalamic GnRH release, which secondarily induce testosterone deficiency (3). Lastly, a different form of hypogonadism is represented by late onset hypogonadism (LOH), a pathological condition occurring in middle-aged and elderly men, characterized by testosterone deficiency and low or normal gonadotropins levels, and a specific clinical

Abbreviations: IR, insulin resistance; MetS, metabolic syndrome; T2-DM, type-2 diabetes mellitus; Hyper-H, hypergonadotropic hypogonadism; Hypo$\mathrm{H}$, hypogonadotropic hypogonadism; GnRH, gonadotropin releasing hormone; $\mathrm{LOH}$, late onset hypogonadism; TRT, testosterone replacement therapy; TT, total testosterone; FT, free testosterone; SHBG, sex hormone-binding globulin; BMI, body mass index; WC, waist circumference; VAT, visceral adipose tissue; TNF-a; IL-6, interleukin-6; IL-1b, interleukin-1b; LH, luteinizing hormone; HPT, hypothalamus-pituitary-testis; ADT, androgen deprivation therapy; GnRHa, gonadotropin releasing hormone analogs; HDL, high-density lipoprotein; T1-DM, type-1 diabetes mellitus; DEXA, dual-energy x-ray absorptiometry; MRI, magnetic resonance imaging. syndrome, which is often associated with, or caused, by age-related metabolic disorders (4). In the last few years, a different classification of hypogonadism has emerged, based on the concept of "organic hypogonadism," as opposed to the concept of "functional hypogonadism" (5-7), the latter being defined as "a condition with no recognizable structural intrinsic hypothalamus-pituitary-testis axis pathology and no specific pathologic conditions suppressing the axis" (5-7). In functional hypogonadism, testosterone levels are borderline and fluctuate around the lower limit of normality, and might be occasionally severely low, whereas gonadotropins are usually within the normal range, occasionally below the normal range (6). A causal relationship between testosterone deficiency and the clinical syndrome of functional hypogonadism is uncertain, since it is more often associated to morbidities affecting the hypothalamus-pituitary-testis activity, such as obesity, MetS or T2-DM, or to aging, although the mild testosterone decline occurring with aging is considered mostly due to accumulation of morbidities (5-7).

A crucial aspect of Hypo-H is represented by a strict link between testosterone deficiency and metabolic disorders, which, especially in $\mathrm{LOH}$ and functional hypogonadism, is characterized by a bidirectional relationship. Indeed, observational studies and metanalyses demonstrated that hypogonadism, in particular testosterone deficiency, is associated with metabolic disorders, and predicts an increased risk of developing incident MetS (8-11) and T2-DM (11-13). On the other hand, observational studies demonstrated that obesity, mainly characterized by visceral adiposity, IR $(14,15)$, MetS (14-16), as well as T2-DM $(14,17,18)$ are often associated with testosterone deficiency and predicts an increased risk of developing incident hypogonadism.

Moreover, additional studies highlighted that the association of testosterone deficiency with metabolic disorders frequently occurs in a clinical context of Hypo- $\mathrm{H}$, and that Hypo- $\mathrm{H}$ is frequently reported in metabolic disorders, such as obesity, IR, MetS, and T2-DM $(15,19,20)$. LOH is typically associated with metabolic disorders $(4,21)$, and has been hypothesized to link obesity, IR and MetS, and T2-DM to sexual dysfunction, the most common symptom of $\operatorname{LOH}(2,22)$. Moreover, in $\mathrm{LOH}$, a bidirectional relationship has been described between hypogonadism, which contributes to increase visceral obesity, and obesity, which contributes to worsen the condition of Hypo-H (23).

Treatment options for Hypo-H and its related metabolic disorders include testosterone replacement therapy (TRT), as well as alternative therapeutic approaches, suitable to contemporarily normalize testosterone levels and restore fertility. These alternative options include human chorionic gonadotropin, and off-label therapies, such as aromatase 
inhibitors and selective estrogen receptor modulators (24). Moreover, the insulin sensitizer metformin has been reported to improve not only metabolic profile but also androgenic status and semen quality in small interventional studies in men with impairment of insulin sensitivity (25) and in men with Hypo-H and impairment of spermatogenesis (26). These alternative therapies grant an increase of testosterone levels, combined to an improvement of semen quality, and, eventually, of metabolic profile, by avoiding the main side effects potentially linked to long-term TRT, which mainly include inhibition of spermatogenesis, pathological increase of erythropoiesis, and prostate hypertrophy (24). In particular, despite TRT was associated with a significant short-term increase in prostate volume, particularly in patients with severe pre-treatment testosterone deficiency, without risk of developing prostate cancer in long-term studies (5), given the androgen-responsive nature of prostate cancer, caution is recommended in the administration of TRT, in cases with overt or suspected prostate cancer, by limiting TRT only to symptomatic hypogonadal patients successfully treated for prostate cancer, after a prudent interval (27).

The current review aims at exploring the association between Hypo- $\mathrm{H}$ and metabolic disorders, by describing the potential, independent, pathogenetic roles of testosterone deficiency and/or metabolic alterations, in the context of the strict relationship between hypogonadism and metabolic diseases, which, in functional hypogonadism and $\mathrm{LOH}$, has been described as a vicious circle. In summary, the current review describes: (1) the consequence of hypogonadism, and, particularly, testosterone deficiency, on metabolic profile; (2) the consequence of metabolic disorders on androgenic status; (3) the effects of TRT on metabolic profile; (4) the effects of metabolic disorders correction on androgenic status.

\section{METABOLIC DISORDERS AND HYPOGONADOTROPIC HYPOGONADISM: OBSERVATIONAL STUDIES}

Compelling evidences from longitudinal studies and metanalyses demonstrated that hypogonadism, in particular testosterone deficiency, is associated with metabolic disorders, and predicts an increased risk of developing MetS and T2-DM (8-13). A population-based prospective cohort study on 702 middle-aged men without MetS or T2-DM at baseline demonstrated that men with total testosterone (TT) or calculated free testosterone (FT) or sex hormone binding globulin (SHBG) levels in the lowest quartile had an increased risk of developing MetS, when compared with men in the higher quartiles, after 11 years of follow-up, although, after adjusting for potential confounders, including correlates of IR, such as body mass index (BMI), waist circumference (WC), insulin levels, and including components of MetS, such as glucose and triglyceride levels and systolic blood pressure, the association of calculated FT with increased risk for MetS was lost (11). A different study with a 15years follow-up on 950 healthy aging men confirmed these results, by highlighting a progressive increase of odds for MetS along TT, FT, and SHBG levels quartiles, from the first to the fourth quartile (9). Likewise, an increased risk of developing T2-DM was demonstrated in healthy men in the lowest quartile compared to those in the highest three quartiles of TT levels (13).

The exact pathophysiological mechanism by which testosterone deficiency leads to metabolic impairment, therefore contributing to obesity, IR, MetS, and T2DM is still unclear. However, testosterone deficiency has been proposed to induce an increase in lipoprotein lipase activity, resulting in increased fatty acids uptake and triglyceride formation in adipocytes, which ultimately stimulate adipocyte proliferation and accumulation of adipose tissue, particularly visceral adipose tissue (VAT) $(28,29)$, therefore explaining the development of obesity, particularly visceral obesity, IR and MetS in patients with hypogonadism. Moreover, the upregulation of multiple mitochondrial enzymes, consequently determining a global impairment of mitochondrial function, has been proposed to contribute to the development not only of fatigue, but also IR, MetS, and T2-DM, in men with hypogonadism (30). On the other side, experimental animal models demonstrated that insulin exerts a stimulatory action on hypothalamic $\mathrm{GnRH}$ neurons, which results in gonadotropin release, therefore suggesting that IR associated with metabolic disorders might reduce gonadotropin secretion and promote hypogonadism (31). Moreover, VAT accumulation characterizing visceral obesity, results in increased aromatization of testosterone to estradiol $(28,30,32)$ and enhanced action of inflammatory mediators, including tumor necrosis factor-a (TNF-a), interleukin-6 (IL-6), and interleukin-1b (IL-1b), shown to suppress hypothalamic $\mathrm{GnRH}$, and, consequently, pituitary luteinizing hormone (LH) secretion in experimental in vitro and in vivo studies $(33,34)$, with induction of testosterone deficiency. Lastly, a decrease of testosterone levels is also promoted by leptin through a direct inhibitory effect on Leydig cells, as suggested by human models (35), as well as indirectly through a leptin-resistance mechanism at the hypothalamic-pituitary level, probably mediated by down-regulation of leptin receptor, as suggested by murine models (36).

A crucial role in the crosstalk between metabolic disorders and testosterone deficiency has been attributed to SHBG levels, which have been shown to be reduced in obese men (37) and men with T2-DM (38), as well as to be negatively associated with the risk of MetS and T2-DM (39). Moreover, visceral adiposity has been pointed out by a recent, large, prospective study, as being negatively correlated with SHBG levels (40). A crucial role for IR, and compensatory hyperinsulinemia, in the suppression of SHBG levels has been strongly supported by a clear inverse relationship between serum insulin and SHBG levels $(38,41,42)$. Lastly, evidences from experimental and clinical studies demonstrated that SHBG is downregulated by pro-inflammatory cytokines, such as TNF-a and IL-1b (39), therefore suggesting that these factors might play a role in the reduction of SHBG levels in chronic inflammatory diseases, such as obesity and diabetes, characterized by increased levels of proinflammatory cytokines. The reduction of SHBG levels might 
result in temporary increase of FT levels, which might enhance aromatase activity, already increased by the VAT accumulation, therefore emphasizing the conversion to estradiol (41), which exerts a negative feedback on the HPT axis, ultimately inducing a reduction of TT and FT levels that remain associated with the reduction of SHBG levels.

In conclusion, testosterone deficiency promotes obesity, especially visceral obesity, IR, MetS and T2-DM, which in turn contribute to a further reduction of testosterone levels, determined by (1) IR-mediated and pro-inflammatory cytokinemediated decrease of SHBG levels, ultimately resulting in negative feedback on the HPT axis; (2) direct inhibitory effect of increased leptin levels on Leydig cells; and (3) indirect inhibition due to HPT axis suppression induced not only by estradiol excess but also by inflammatory mediators, leptin resistance and IR. The combinations of these mechanisms induces the determination of a substantial Hypo-H. A graphical overview of the relationship between testosterone deficiency and metabolic disorders is depicted in Figure 1.

In the context of Hypo- $\mathrm{H}$, few studies exist in organic, genetic or idiopathic forms of Hypo- $\mathrm{H}$, focused on metabolic profile and on the potential independent role of testosterone deficiency

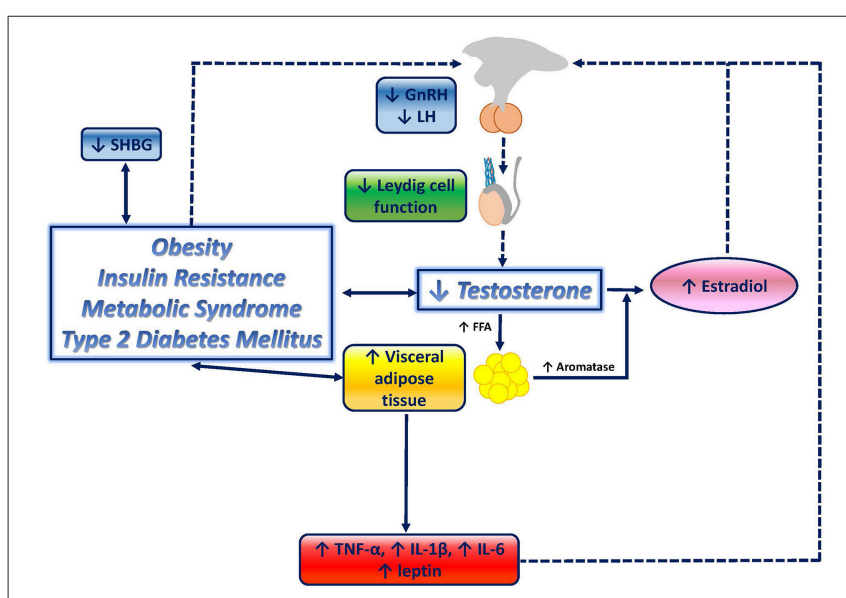

FIGURE 1 | Graphical overview of the relationship between testosterone deficiency and metabolic disorders. Testosterone deficiency determines an increase in lipoprotein lipase activity, resulting in increased fatty acids (FFA) uptake and triglyceride levels in adipocytes, which ultimately stimulate adipocyte proliferation and visceral adipose tissue (VAT) increase, and therefore, contribute to the onset of visceral obesity. VAT accumulation triggers several downstream mechanisms which contribute to further impair the metabolic profile, and, potentially, enhances testosterone deficiency by closing the loop: increased aromatase activity results in increased conversion of testosterone to estradiol; inflammatory mediators, known to be increased in metabolic disorders, including tumor necrosis factor-a (TNF-a), interleukin-6 (IL-6), and interleukin-1b (IL-1b), have been shown to suppress hypothalamic gonadotropin releasing hormone $(\mathrm{GnRH})$, and consequently, pituitary luteinizing hormone $(\mathrm{LH})$ and testosterone secretion; increased leptin levels exert direct inhibitory effects on Leydig cells; leptin resistance at the hypothalamic-pituitary level, mediated by reduced LH release, boosts testosterone suppression; insulin resistance (IR) associated with obesity, metabolic syndrome and type-2 diabetes mellitus has been suggested to reduce gonadotropin secretion, therefore contributing to testosterone deficiency, and to reduce sex hormone binding globulin (SHBG). in the development of metabolic disorders; nevertheless, hypogonadism due to deficient production, secretion, or action of $\mathrm{GnRH}$, as well as pharmacologically-induced hypogonadism for androgen deprivation therapy (ADT), might represent suitable clinical models of Hypo- $\mathrm{H}$, with available evidence of testosterone deficiency-induced metabolic disorders. Interestingly, one prospective cohort study on 12 young men with idiopathic GnRH deficiency demonstrated that insulin sensitivity was significantly reduced, and fasting insulin and IR, as assessed by HOMA-IR, were significantly increased, after 2 weeks of acute TRT withdrawal (43), demonstrating that testosterone deficiency might independently increase IR. Indeed, acute castration in patients with $\mathrm{GnRH}$ deficiency, achieved by withdrawing TRT, enables the assessment of the independent effects of acute changes in circulating testosterone levels, by dissecting the potentially confounding effects of changes in body composition and metabolism, which can be induced by long-term castration interventions (44), such as ADT with $\mathrm{GnRH}$ analogs (GnRHa), in men with androgen-sensitive prostate cancer (45-47). ADT-induced Hypo-H in men with prostate cancer has been associated with increased fat mass (45-47), decreased insulin sensitivity $(45,48)$, and increased risk of MetS and T2-DM (49). Moreover, differently from classical MetS, ADT-induced Hypo-H is associated with increased, rather than decreased, high-density lipoprotein (HDL) levels, and a preferential increase in subcutaneous adipose tissue, rather than VAT (47). Lastly, a large population-based cohort study on elderly men with prostate cancer demonstrated that ADTinduced Hypo-H was associated with a significantly increased risk of T2-DM (50). Further evidences supporting the hypothesis of a direct and independent role of testosterone deficiency in the impairment of metabolic profile, derive from a review of clinical cases with heterogeneous pathological conditions, such as congenital Hypo- $\mathrm{H}$, Klinefelter syndrome, and male to female or female to male transexualism, associated with a different severity of testosterone deficiency, in a context of either organic or functional hypogonadism, which highlighted that long-term hypogonadism, even if mild, might contribute to the onset of obesity, IR and MetS (51).

A more conspicuous literature exists, concerning the strict and bidirectional relationship between functional Hypo- $\mathrm{H}$, and mainly in LOH, and metabolic disorders, including obesity, MetS, and T2-DM.

Several studies highlighted that obesity is frequently associated with testosterone levels within the hypogonadal range, and a biochemical picture of Hypo-H $(41,52)$. Indeed, in obese men, SHBG levels may be low, and low TT and/or FT levels have been associated with low or inappropriately normal gonadotropins levels; therefore, a condition defined as male obesity-related Hypo-H might be diagnosed in obese patients presenting with this impairment of HPT axis, along with signs and symptoms of hypogonadism, in absence of an organic impairment of the axis, and recognized causes of hypogonadism (41). Studies addressing TT, FT, and SHBG levels in obese men demonstrated that all were significantly reduced, compared to non-obese men $(53,54)$; moreover, although SHBG levels were similarly decreased in moderately and severely obese men, TT and 
FT levels were significantly lower in the latter group, and testosterone deficiency, according to FT levels, was detected only in severely obese subjects (53). Few studies evaluated body fat distribution in relation to androgenic status. Male obesityrelated Hypo-H itself might worsen obesity, by promoting fat mass increase, which may in turn significantly worsen the hypogonadal condition; in particular, testosterone deficiency has been demonstrated to increase VAT (55). A cross-sectional cohort study on 217 healthy men highlighted that low TT and SHBG levels were reliable predictors of more severe obesity and greater VAT, therefore also suggesting that age-related differences in testosterone levels could be at least partly determined by the concomitant variation in adiposity (56). Consistently, a different cross-sectional cohort study of 23 healthy men reported that VAT was negatively correlated with TT, FT, and SHBG levels (57). Nevertheless, a case-control study on 26 hypogonadal men failed to detect any difference in VAT, although hypogonadal men displayed increased subcutaneous fat mass (58). An important role in male obesity-related Hypo- $\mathrm{H}$ has been attributed to hyperinsulinism, typically associated with obesity, particularly visceral obesity, as demonstrated by a cross-sectional cohort study on 178 men from a larger population-based study on diabetes and cardiovascular disease, in which TT and FT, but not SHBG, levels were negatively correlated with insulin levels, after adjustment for age, obesity, and body fat distribution (59). A different cross-sectional cohort study on 55 obese men confirmed the negative correlation between TT and FT and insulin levels, and reported a negative correlation with insulin levels also for SHBG; these correlations were maintained, independently from BMI (60). Moreover, a cross-sectional cohort study on 1,292 healthy non-diabetic men demonstrated a negative correlation between TT and insulin levels, maintained after adjustment for age and obesity (61). These evidences strongly support the existence of a strict link between testosterone levels and insulin sensitivity, not necessarily correlated with underlying obesity.

Some studies demonstrated that MetS is associated with testosterone deficiency, in particular in presence of obesity (59, $62,63)$. Indeed one study on 864 men with mean age of 52 years demonstrated that obese men with MetS, particularly those with severe obesity, have significantly decreased TT levels, compared to healthy men (62); specifically, in multiple linear regression models a significant negative association was found between TT levels and 3 out of 5 of MetS definition criteria, namely, diabetes or fasting glucose levels $>110 \mathrm{mg} / \mathrm{dl}$, triglycerides levels $\geq 150$ $\mathrm{mg} / \mathrm{dl}$, as well as BMI $\geq 30 \mathrm{~kg} / \mathrm{m}^{2}$ (62). Moreover, a population based, prospective cohort study on 1,896 men with mean age of 52 years demonstrated that TT, FT, and SHBG levels were significantly lower in men with MetS compared to men without MetS, and that men in the lowest tertile for FT levels were more likely to have MetS, after adjusting for age and BMI (16). In this study, low testosterone and SHBG levels were associated with MetS independently from BMI, and in particular TT, FT, and SHBG levels were negatively correlated with insulin, glucose, and triglycerides, and positively correlated with HDL-cholesterol levels (16). Lastly, in a different study on 87 healthy men TT, FT, and SHBG levels were found to be positively correlated to total whole body glucose disposal (64).

Several studies reported that T2-DM is associated with testosterone deficiency $(2,65)$ and that both TT and FT levels, as well as SHBG levels, were reduced in patients with T2DM $(19,66)$; moreover, in patients with T2-DM, testosterone deficiency, often associated with low or inappropriately normal levels of gonadotropins, particularly LH, might contribute to worsen sexual dysfunction $(67,68)$. The first study focusing on Hypo-H in T2-DM, a cross-sectional cohort study performed on 103 men, reported a high prevalence of subnormal FT (33\%), and low levels of gonadotropins, confirming the presence of an underlying hypothalamic-pituitary disorder, rather than a defect within the testis (19). Moreover, an inverse relationship was found between TT, FT, and SHBG with BMI (19), also confirmed by subsequent studies $(21,22)$. A cross-sectional cohort study on 355 men with T2-DM confirmed a high prevalence of Hypo-H in T2-DM patients, defined as low TT and FT levels, and low or inappropriately normal LH levels; moreover, by including the assessment of prevalence of symptoms related to hypogonadism, a prevalence of $17 \%$ and $14 \%$ of hypogonadism was found, when considering low TT or low FT, respectively (28). A large study on 2098 men demonstrated that the prevalence of Hypo$\mathrm{H}$, with decreased TT, FT, and SHBG, was significantly higher in T2-DM patients, rather than patients without T2-DM (69). A different cross-sectional study on 580 men reported a prevalence of testosterone deficiency of $43 \%$ and $57 \%$, by considering TT and calculated FT, respectively, in T2-DM, and of 7\% and 20\% in type-1 diabetes mellitus (T1-DM) (66). Nevertheless, another study failed to demonstrate testosterone deficiency occurrence in T1-DM, despite a negative correlation between TT and FT, but not SHBG, levels and BMI was reported (20). Lastly, consistently with different studies in non-diabetic normal or overweight men with or without MetS $(70,71)$, calculated FT levels were negatively correlated with insulin levels, HOMA-IR and VAT, also in a cross-sectional cohort study on men with T2-DM, further supporting the hypothesis that IR reduces circulating testosterone levels, and that reduced circulating testosterone, in turn, contributes to increase IR (66). Consistently, a crosssectional cohort study on men with T2-DM and erectile dysfunction reported that $86 \%$ of men displaying subnormal FT levels had Hypo-H, suggesting that Hypo-H is the most common gonadal dysfunction in diabetic men affected by erectile dysfunction (68).

In conclusion, consistent evidences from clinical and experimental studies support the concept that Hypo- $\mathrm{H}$ may be an independent risk factor for metabolic disorders; moreover, specifically in LOH, a vicious circle hypothesis has been repeatedly demonstrated, linking Hypo-H to obesity, IR, MetS, and T2-DM in a bidirectional relationship, in which visceral obesity and IR seem to be the major pathophysiological players; this evidence confirmed that, besides TT, calculated FT has to be considered as a crucial endpoint to be assessed in patients with metabolic disorders, due to the effect of visceral obesity and IR on SHBG and, consequently, on FT and downstream FT actions. 


\section{INTERVENTIONAL STUDIES IN PATIENTS WITH HYPOGONADISM: EFFECTS ON METABOLIC DISORDERS}

Several studies in cohorts of men with hypogonadism of various etiology, including Hypo-H, Hyper-H, LOH, or mixed cohorts, focused on the effects of TRT on metabolic parameters. Overall, the results of these studies demonstrated that normalization of testosterone levels in obese men reduces body weight, BMI, WC, and fat mass (72-76). Moreover, metanalyses of studies on hypogonadal men with T2-DM highlighted that TRT is associated with marked reduction in WC, as well as indexes of T2-DM, suggesting that TRT may ameliorate visceral obesity and improve metabolic control in patients with hypogonadism (18, $21,77)$. In particular, one prospective study on 55 men with mean age 60.5 years and a diagnosis of $\mathrm{LOH}$, generally associated with MetS and T2-DM, demonstrated that a 9-months treatment with long-acting intramuscular testosterone undecanoate $(1,000 \mathrm{mg}$ at weeks 0 and 6 and thereafter every 12 weeks) or transdermal testosterone gel $50 \mathrm{mg} /$ day, significantly reduced WC (78). These results were confirmed by a similar single-blind randomized study on 32 hypogonadal men with mean age 56.6 years and MetS and newly diagnosed T2-DM, receiving a combination of 52-weeks transdermal testosterone gel $50 \mathrm{mg} /$ day and supervised diet and exercise or receiving supervised diet and exercise but not testosterone treatment (79). A different, double-blind placebo-controlled study on 184 hypogonadal men with MetS demonstrated a significant improvement in body weight, BMI and WC, following testosterone undecanoate $(1,000 \mathrm{mg}$ at weeks 0,6 , and 18) administration, aimed at restoring normal testosterone levels, for 30 weeks (80). Some studies failed to demonstrate a significant decline in fat mass (81-83), or visceral obesity (84-86), despite an overall improvement of body composition following testosterone treatment; the majority of these studies did not address regional fat distribution as an issue. However, several studies demonstrated that testosterone treatment in men with normal and low-normal testosterone levels or clinical hypogonadism improves body composition not only by increasing lean mass, but also by decreasing fat mass. In one double-blind, randomized dose-response study on 54 healthy eugonadal men aged 18-35 years, treatment with weekly injections of testosterone enanthate at different doses (25-600 mg) for 20 weeks significantly increased total body lean mass, as well as appendices and trunk lean mass, at the highest doses $(125,300,600 \mathrm{mg})(87)$. On the other hand a double-blind, randomized, placebo-controlled study on 60 nonobese hypogonadal men over 55 years of age demonstrated that transdermal testosterone treatment at $5 \mathrm{mg} /$ day for 52 weeks resulted in a significantly decreased VAT, compared to untreated men, assessed at dual energy x-ray absorptiometry (DEXA), without change in total body or abdominal subcutaneous fat mass, suggesting a protective effect of testosterone specifically from VAT gain (88). Indeed, despite a consistent positive effect of TRT on body composition, few studies addressed site-specific adipose tissue depot after TRT, by reporting controversial results. In particular, one case-control study on 36 hypogonadal men, comprising 29 men with Hypo-H (20 with known cause and 9 idiopathic), and 7 men with Hyper-H, aged 22-68 years (median age 53 years), highlighted that TRT with $100 \mathrm{mg}$ intramuscular testosterone enanthate once per week for 18 months significantly decreased total body and subcutaneous fat mass, whereas VAT was reduced but change did not reach statistical significance, as assessed at quantitative computed tomography (89). Conversely, another double-blind randomized placebo-controlled study on 108 healthy men over 65 years of age, with testosterone levels $1 \mathrm{SD}$ or more below the mean for normal young men $(<475 \mathrm{ng} / \mathrm{dL})$, demonstrated that treatment with transdermal testosterone at $6 \mathrm{mg} / \mathrm{day}$ aimed at raising testosterone levels to mid-normal young men range, significantly reduced total body fat mass and fat mass within arms and legs depot, but not VAT, as assessed by regional DEXA, during a 36-months treatment (90). By contrast, in two different studies on men over 60 years of age, androgen treatment preferentially induced a reduction in fat mass within the trunk (91), or an equivalent reduction within both the trunk and the appendices (92), as assessed at DEXA and magnetic resonance imaging (MRI). Suggestively, a double-blind randomized placebo-controlled study on 32 hypogonadal and T2-DM-affected men demonstrated that TRT with $250 \mathrm{mg}$ intramuscular testosterone every 2 weeks reversed downregulation of androgen and estrogen receptors, and aromatase expression in the adipose tissue, which characterized this cohort of patients at baseline (93). Inconsistency of results among studies may rely on differences in testosterone formulations, study population, and specific outcome measures of regional fat distribution.

Small interventional studies evaluated the effects of testosterone treatment on insulin sensitivity in different cohorts of patients, including obese, T2-DM, hypogonadal, and eugonadal men; these studies reported conflicting results, probably due to heterogeneity in dose and duration of testosterone treatment, as well as target cohorts. An inverse relationship between insulin sensitivity and testosterone levels was demonstrated by several studies on obese men and men with T2-DM. A controlled trial on 23 middle-aged men with visceral obesity demonstrated that testosterone treatment with $80 \mathrm{mg}$ oral testosterone undecanoate twice a day for 8 months ameliorated insulin sensitivity, as displayed by a significantly increased glucose disposal rate, measured by hyperinsulinemiceuglycemic clamp, and also significantly reduced VAT, without changes in body mass, as assessed at computed tomography (76). A different study on a similar cohort highlighted a more impressive global effect; in particular, testosterone treatment with transdermal testosterone or dihydrotestosterone for 3 months significantly increased glucose uptake, as assessed by hyperinsulinemic-euglycemic clamp and significantly decreased waist/hip ratio, without changes in body fat mass, therefore displaying improvement of insulin sensitivity (73). Additionally, a double-blind, randomized, placebo-controlled trial on 18 healthy non-obese hypogonadal men demonstrated that treatment with dihydrotestosterone gel at $35 \mathrm{mg} /$ day for 3 months, aimed at normalizing testosterone levels, significantly 
reduced insulin and leptin levels, and improved HOMAIR (94). A double-blind randomized crossover study on 24 hypogonadal men (2 Hypo- $\mathrm{H}, 8$ Hyper- $\mathrm{H}, 14$ mixed) with T2-DM demonstrated that TRT with $200 \mathrm{mg}$ intramuscular testosterone propionate every 2 weeks for 3 months significantly reduced $\mathrm{HbAlc}$ and glucose levels, WC and waist/hip ratio, and significantly improved HOMA-IR, in patients not treated with insulin therapy, with a reduction of insulin dosing in $50 \%$ of insulin-treated patients (95). Another double-blind randomized placebo-controlled trial on 84 men with T2-DM (50 eugonadal and 34 with Hypo-H) showed that a 24 -weeks TRT with $250 \mathrm{mg}$ intramuscular testosterone cypionate every 2 weeks improved insulin sensitivity, assessed through hyperinsulinemiceuglycemic clamp, and also induced a decrease of subcutaneous fat, measured by DEXA and MRI, although VAT was not affected by TRT (96). Conversely, different studies failed to demonstrate an improvement in insulin sensitivity in different cohorts of patients. In particular, a small uncontrolled study on 30 eugonadal non-obese men aged 27-30 years showed no effect of supra-physiological testosterone treatment with $100 \mathrm{mg}$ or $300 \mathrm{mg}$ intramuscular testosterone enanthate or with $100 \mathrm{mg}$ or $300 \mathrm{mg}$ 19-nortestosterone decanoate administered once per week for 6 weeks on waist/hip ratio, fasting glucose and insulin levels, and response to the oral glucose tolerance test (97). A double-blind randomized placebo-controlled study on 134 non-diabetic non-obese men over or of 60 years of age, with low or low-normal testosterone levels demonstrated that a 36-months testosterone treatment with daily testosterone gel $1 \%$, at initial dose $7.5 \mathrm{~g}$ with dose titration according to TT levels, did not improve insulin sensitivity, as demonstrated by unchanged steady-state plasma glucose concentration at equilibrium, a direct measure of the ability of exogenous insulin to mediate disposal of an infused glucose load under steady-state conditions, during which endogenous insulin secretion has been suppressed by octreotide administration (98). A different small uncontrolled study on 10 hypogonadal men with T2-DM failed to find an effect of TRT with $150 \mathrm{mg}$ intramuscular testosterone enanthate every 2 weeks for 6 months, on the control of diabetes, and fasting glucose or insulin levels (99). Lastly, a small uncontrolled study on 10 men aged 19-27 years with idiopathic Hypo-H demonstrated lack of an effect of TRT with intramuscular testosterone enanthate administered at $100 \mathrm{mg}$ dose every 2 weeks ( 3 injections) and then at $200 \mathrm{mg}$ dose every 2 weeks (3 injections), on waist/hip ratio or IR, measured by hyperinsulinemic-euglycemic clamp (100).

In conclusion, the effect of testosterone on adipose tissue and insulin sensitivity seems to vary according to dose and duration of testosterone treatment, as well as to testosterone type and formulation, and to the characteristics of target populations; it might be hypothesized that the improvement of IR might be determined by an increase in lean body mass, and a decrease in adipose tissue, or, more specifically, by a decrease in VAT, an action which is more remarkable in hypogonadal men.

A summary at a glance of the main interventional studies evaluating the effects of testosterone treatment on anthropometric indexes and metabolic profile, in hypogonadal, and also eugonadal, men, with or without obesity, MetS, and T2-DM, is provided in Table 1.

\section{INTERVENTIONAL STUDIES IN PATIENTS WITH METABOLIC DISORDERS: EFFECTS ON TESTOSTERONE PRODUCTION}

Several studies in cohorts of men with obesity, MetS, T2-DM, or mixed cohorts, focused on the effects of weight loss and/or drugs used in patients with MetS and T2-DM to control metabolic derangements, on testosterone and gonadotropins levels.

Numerous studies assessed the effects of weight loss, obtained through either diet and lifestyle modifications or bariatric surgery, on testosterone and gonadotropins levels, by demonstrating a greater improvement with the latter approach $(23,101)$. Indeed, a metanalysis of studies on obese men undergoing diet or bariatric surgery concluded that both interventions significantly increased LH, TT, FT, and SHBG levels, with a simultaneous decrease of estradiol levels; in particular, TT variation after low calorie diet-induced or bariatric surgery-induced weight loss reached 2.87 and $8.73 \mathrm{nmol} / \mathrm{L}$, respectively (101). The recognized mechanisms underlying the beneficial effect of weight loss on the androgenic status comprise VAT reduction and consequent decrease of IR, and the reduction of estradiol-induced and leptin-induced negative feedback on the HPT axis (52). Several interventional studies evaluated the effects of drugs used in patients with MetS and T2-DM, namely insulin sensitizers and antidiabetic drugs, on testosterone levels and hypogonadism, and confirmed a strict relationship between obesity and hypogonadism. A small uncontrolled study on 45 men with MetS demonstrated that a 6-months metformin administration at a daily dose starting from $850 \mathrm{mg} /$ day for the first week, gradually increased to $850 \mathrm{mg}$ twice a day in the second week, and subsequently to $850 \mathrm{mg}$ thrice a day, significantly reduced estradiol and SHBG, and increased LH, TT, and FT levels (26). Moreover, in a different small uncontrolled study on 35 men with MetS stratified in 21 eugonadal and 14 hypogonadal men, a 4months metformin administration at a dose of $850 \mathrm{mg}$ twice daily, associated with normo-caloric diet and physical activity, significantly increased both TT and FT levels, irrespective of gonadal status (102). In one small uncontrolled study on 16 hypogonadal men with T2-DM, a 6-months daily administration of rosiglitazone at the dose of $8 \mathrm{mg}$ significantly increased SHBG, TT and calculated FT levels (103). In a multicenter study on 176 obese men with T2-DM, shortterm combined treatment with exenatide plus metformin or glimepiride plus metformin significantly increased TT levels, with a greater efficacy being displayed by the first combination, and testosterone changes being closely correlated to changes in WC (104). These results suggest that antidiabetic drugs with a differential effect on body weight, namely, drugs which increase or reduce body weight, might consistently display a differential effect on androgenic status; nevertheless, scant literature exists investigating the effects of the new classes of antidiabetic drugs with a positive or neutral effect on body 
TABLE 1 | Summary at a glance of interventional studies evaluating the effects of testosterone treatment on anthropometric indexes and metabolic profile, in hypogonadal and eugonadal men, with or without obesity, metabolic syndrome, and type-2 diabetes mellitus.

\begin{tabular}{|c|c|c|c|c|c|}
\hline & $\begin{array}{l}\text { Type } \\
\text { of } \\
\text { study }\end{array}$ & $\begin{array}{l}\text { Patients } \mathrm{n}^{\circ} \text { and } \\
\text { characteristics and } \\
\text { intervention groups }\end{array}$ & Age (years) & $\begin{array}{l}\text { Testosterone treatment } \\
\text { (dose, route, duration) }\end{array}$ & Main outcomes \\
\hline $\begin{array}{l}\text { Heufelder } \\
\text { et al. (79) }\end{array}$ & $\begin{array}{l}\text { B } \\
\text { Rnd }\end{array}$ & $\begin{array}{l}32 \text { hypogonadal men with MetS } \\
\text { and newly diagnosed T2-DM } \\
\text { Group 1: diet and exercise plus } \\
\text { testosterone }(n=16) \\
\text { Group 2: diet and exercise } \\
(n=16)\end{array}$ & $\begin{array}{l}\text { Group 1: m } 57 \pm \\
1.4 \\
\text { Group 2: } \mathrm{m} 56 \\
\pm 1.5\end{array}$ & $\begin{array}{l}\text { Group 1: testosterone gel } 50 \\
\text { mg/day for } 52 \text { wk }\end{array}$ & $\begin{array}{l}\text { WC: Group } 1 \downarrow \text {; Group } 2 \downarrow \text {; } \\
\downarrow \text { Group } 1>\downarrow \text { Group } 2 \\
\text { HI: Group } 1 \downarrow \text {; Group } 2 \downarrow \text {; } \\
\downarrow \text { Group } 1>\downarrow \text { Group } 2(p<0.001) \\
\text { FPI: Group } 1 \downarrow \text {; Group } 2 \downarrow \text {; } \\
\downarrow \text { Group } 1>\downarrow \text { Group } 2(p<0.001) \\
\text { FBG: Group } 1 \downarrow \text {; Group } 2 \downarrow \text {; } \\
\downarrow \text { Group } 1=\downarrow \text { Group } 2\end{array}$ \\
\hline $\begin{array}{l}\text { Woodhouse } \\
\text { et al. (87) }\end{array}$ & $\begin{array}{l}\text { DB } \\
\text { Rnd }\end{array}$ & $\begin{array}{l}54 \text { healthy eugonadal men } \\
\text { Group 1: testosterone } \\
25 \mathrm{mg}(n=11) \\
\text { Group 2: testosterone } \\
50 \mathrm{mg}(n=8) \\
\text { Group 3: testosterone } \\
125 \mathrm{mg}(n=12) \\
\text { Group 4: testosterone } \\
300 \mathrm{mg}(n=10) \\
\text { Group 5: testosterone } \\
600 \mathrm{mg}(n=13)\end{array}$ & $\begin{array}{l}\mathrm{m} 27 \pm 4 \\
(\mathrm{R} 18-35)\end{array}$ & $\begin{array}{l}\text { Monthly injections of GnRH } \\
\text { agonist in all groups } \\
\text { Group 1: testosterone enanthate } \\
25 \mathrm{mg} \text { IM every wk for } 20 \text { wk } \\
\text { Group 2: testosterone enanthate } \\
50 \mathrm{mg} \text { IM every wk for } 20 \text { wk } \\
\text { Group 3: testosterone enanthate } \\
125 \mathrm{mg} \text { IM every wk for } 20 \text { wk } \\
\text { Group 4: testosterone enanthate } \\
300 \mathrm{mg} \text { IM every wk for } 20 \text { wk } \\
\text { Group 5: testosterone enanthate } \\
600 \mathrm{mg} \text { IM every wk for } 20 \text { wk }\end{array}$ & $\begin{array}{l}\text { VAT: Group } 1 \uparrow(p<0.05) ; \\
\text { Group } 2 \uparrow(p<0.05) ; \\
\text { Group } 3=; \\
\text { Group } 4=; \\
\text { Group } 5= \\
\text { LBM: Group } 1=; \\
\text { Group } 2=; \\
\text { Group } 3 \uparrow(p<0.01) ; \\
\text { Group } 4 \uparrow(p<0.001) \\
\text { Group } 5 \uparrow(p<0.001)\end{array}$ \\
\hline $\begin{array}{l}\text { Katznelson } \\
\text { et al. (89) }\end{array}$ & $\mathrm{CC}$ & $\begin{array}{l}\text { Group 1: } 36 \text { hypogonadal men } \\
\text { (29 Hypo- } \mathrm{H} ; 7 \text { Hyper-H) } \\
\text { Group 2: } 44 \text { eugonadal men }\end{array}$ & $\begin{array}{l}\text { Group 1: M } 53 \pm 2 \\
\text { Group 2: M } 53 \pm 2\end{array}$ & $\begin{array}{l}\text { Group 1: testosterone enanthate } \\
100 \mathrm{mg} \text { IM every wk for } 18 \mathrm{mt}\end{array}$ & $\begin{array}{l}\text { FMB } \downarrow(p<0.01) \\
\text { SF } \downarrow(p<0.01) \\
\text { VAT }=\end{array}$ \\
\hline $\begin{array}{l}\text { Snyder } \\
\text { et al. (90) }\end{array}$ & $\begin{array}{l}\text { DB } \\
\text { Rnd } \\
\text { PCT }\end{array}$ & $\begin{array}{l}108 \text { healthy men with } \\
\text { testosterone levels } 1 \mathrm{SD} \text { or more } \\
\text { below the mean for normal } \\
\text { young men }(<475 \mathrm{ng} / \mathrm{dL}) \\
\text { ( } 96 \text { men completed the protocol) } \\
\text { Group 1: testosterone } \\
\text { Group 2: placebo }\end{array}$ & $>65$ & $\begin{array}{l}\text { Group 1: transdermal } \\
\text { testosterone } 6 \mathrm{mg} / \text { day for } 36 \mathrm{mt} \\
\text { Group 2: placebo }\end{array}$ & $\begin{array}{l}\mathrm{FBM} \downarrow(p=0.001) \\
\mathrm{SF} \downarrow(p<0.001) \\
\operatorname{VAT}= \\
\operatorname{LBM} \uparrow(p<0.001)\end{array}$ \\
\hline
\end{tabular}


TABLE 1 | Continued

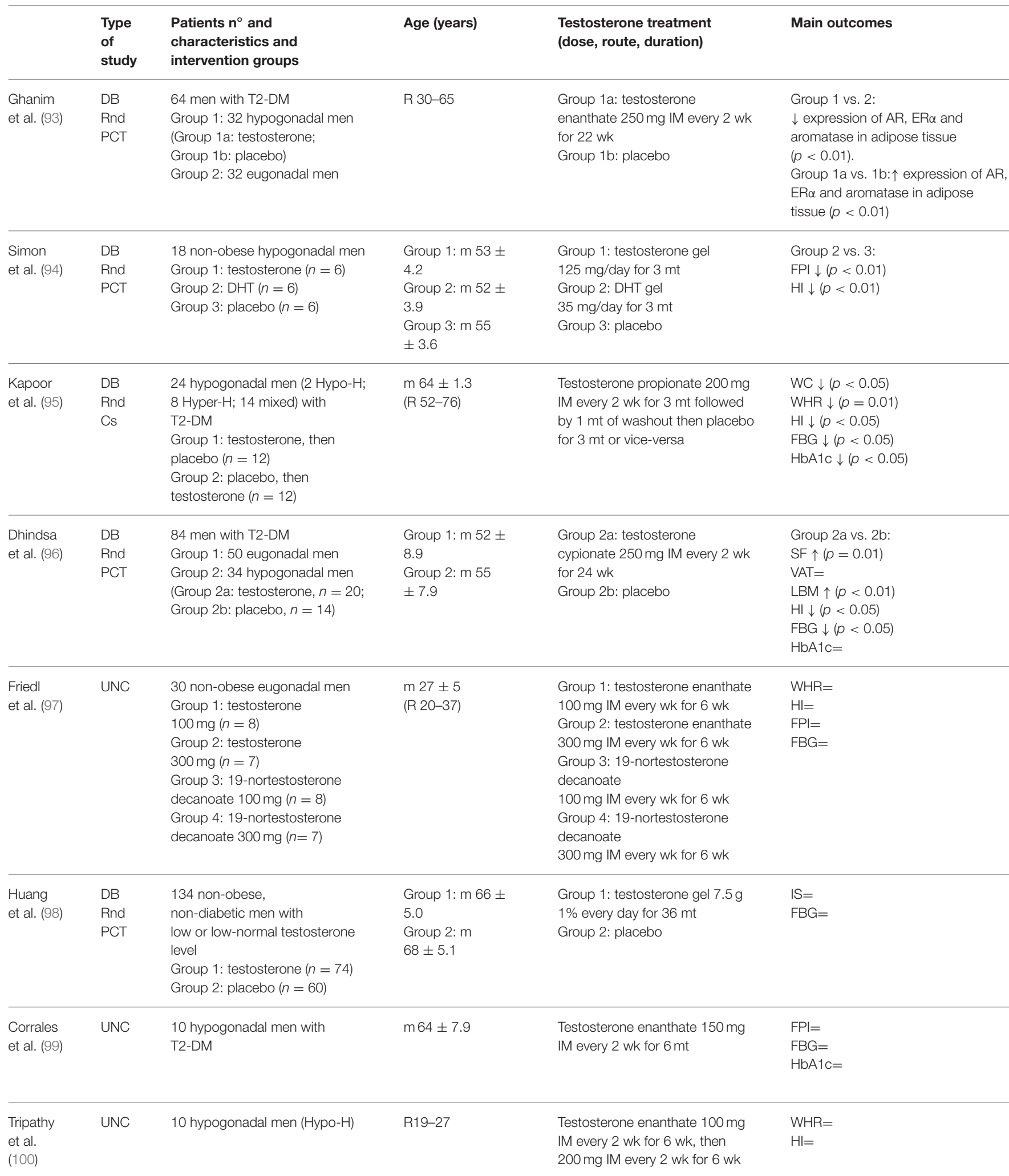

CC, case-control; UNC, uncontrolled cohort; P, prospective; PCT, Placebo Controlled Trial; Rnd, randomized; B, blind; DB, double blind; CS, crossover; Hypo-H, Hypogonadotropic hypogonadism; Hyper-H, Hypergonadotropic Hypogonadism; BW, body weight; WC, waist circumference; BMI, body mass index; WHR, Waist/Hip Ratio; IS, Insulin Sensitivity; HI, HOMA-Index; FBG, Fasting Blood Glucose; HbA1c, Glycated hemoglobin; FPI, Fasting Plasma Insulin; LBM, Lean Body Mass; FBM, Fat Body Mass; SF, Subcutaneous Fat; VAT, Visceral Adipose Tissue; AR, Androgen receptor; ERa, Estrogen Receptor; MetS, Metabolic Syndrome; T2-DM, type-2 diabetes mellitus; $R$, range; $m$, mean; $M$, median; DHT, dihydrotestosterone; IM, intramuscular; wk, week; $m t$, month; $\downarrow$, reduction; $\uparrow$, increase; =, no change. 
weight on testosterone levels. One study on 30 men with obesity-associated hypogonadism demonstrated that liraglutide administered for 16 weeks at a daily dose of $0.6 \mathrm{mg}$, and weekly titrated up to $3 \mathrm{mg}$, significantly increased gonadotropins and TT levels (105). Moreover, a different study on 45 obese and diabetic hypogonadal men demonstrated that adding liraglutide to lifestyle changes, metformin and testosterone treatment, in patients with insufficient metabolic control, significantly increased testosterone levels until normalization by means of improved body weight and glycemic control (106).

\section{CONCLUSIONS}

The current review highlights that Hypo-H might contribute to the development or worsening of metabolic conditions, mainly through the increase of visceral adiposity and IR, and that metabolic disorders, including obesity, IR, MetS, and T2-DM, contribute to the development or worsening of testosterone deficiency, which is frequently associated with low or inappropriately normal gonadotropins, therefore hinting to Hypo-H, rather than Hyper-H. Moreover, whereas an independent role of testosterone deficiency in the pathogenesis of metabolic disorders has been indirectly suggested in men with Hypo- $\mathrm{H}$, in functional forms of Hypo- $\mathrm{H}$, particularly in $\mathrm{LOH}$, the existence of a bidirectional causal relationship between testosterone and metabolic derangement has been

\section{REFERENCES}

1. Basaria S. Male hypogonadism. Lancet. (2014) 383:1250-63. doi: 10.1016/S0140-6736(13)61126-5

2. Corona G, Bianchini S, Sforza A, Vignozzi L, Maggi M. Hypogonadism as a possible link between metabolic diseases and erectile dysfunction in aging men. Hormones (Athens). (2015) 14:569-78. doi: 10.14310/horm.2002.1635

3. Bonomi M, Vezzoli V, Krausz C, Guizzardi F, Vezzani S, Simoni M, et al. Characteristics of a nationwide cohort of patients presenting with isolated hypogonadotropic hypogonadism (IHH). Eur J Endocrinol. (2018) 178:2332. doi: 10.1530/EJE-17-0065

4. Bassil N. Late-onset hypogonadism. Med Clin North Am. (2011) 95:507-23. doi: 10.1016/j.mcna.2011.03.001

5. Corona G, Rastrelli G, Reisman Y, Sforza A, Maggi M. The safety of available treatments of male hypogonadism in organic and functional hypogonadism. Expert Opin Drug Saf. (2018) 17:277-92. doi: 10.1080/14740338.2018.1424831

6. Grossmann M, Matsumoto AM. A perspective on middle-aged and older men with functional hypogonadism: focus on holistic management. J Clin Endocrinol Metab. (2017) 102:1067-75. doi: 10.1210/jc.2016-3580

7. Yeap BB, Grossmann M, McLachlan RI, Handelsman DJ, Wittert GA, Conway AJ, et al. Endocrine Society of Australia position statement on male hypogonadism (part 1): assessment and indications for testosterone therapy. Med J Aust. (2016) 205:173-8. doi: 10.5694/mja 16.00393

8. Brand JS, Rovers MM, Yeap BB, Schneider HJ, Tuomainen TP, Haring $\mathrm{R}$, et al. Testosterone, sex hormone-binding globulin and the metabolic syndrome in men: an individual participant data meta-analysis of observational studies. PLOS ONE. 9:e100409. doi: 10.1371/journal.pone.0100409

9. Kupelian V, Hayes FJ, Link CL, Rosen R, McKinlay JB. Inverse association of testosterone and the metabolic syndrome in men is consistent across race and ethnic groups. J Clin Endocrinol Metab. (2008) 93:3403-10. doi: 10.1210/jc.2008-0054 clearly demonstrated. Few interventional studies demonstrate that TRT in hypogonadal men might improve body composition, particularly by decreasing VAT, and might improve insulin sensitivity. On the other hand, correction of metabolic disorders, especially interventions aimed at reducing body weight and IR, ultimately result in an improvement of testosterone levels and HPT axis function. Nevertheless, further observational studies on men with Hypo-H, and larger clinical trials with TRT are required, to definitely clarify the independent pathogenic role of testosterone deficiency in metabolic disorders, in the context of Hypo- $\mathrm{H}$, and to better define the potential beneficial effects of TRT in Hypo-H-related metabolic features.

\section{AUTHOR CONTRIBUTIONS}

$\mathrm{RP}$ conceived all aspects of the manuscript, performed literature search, and wrote the manuscript. DM and ER significantly contributed to manuscript drafting and writing. FG and MM significantly contributed to manuscript revision during peer review process. CdA critically revised the first original draft and any other version of the manuscript before and after peer review process, and provided significant content contribution and English language support. AC critically revised and reviewed the manuscript for important intellectual content. All authors contributed to manuscript revision, read, and approved the submitted version.

10. Kupelian V, Page ST, Araujo AB, Travison TG, Bremner WJ, McKinlay JB. Low sex hormone-binding globulin, total testosterone, and symptomatic androgen deficiency are associated with development of the metabolic syndrome in nonobese men. J Clin Endocrinol Metab. (2006) 91:843-50. doi: $10.1210 /$ jc. $2005-1326$

11. Laaksonen DE, Niskanen L, Punnonen K, Nyyssönen K, Tuomainen TP, Valkonen VP, et al. Testosterone and sex hormone-binding globulin predict the metabolic syndrome and diabetes in middle-aged men. Diabetes Care. (2004) 27:1036-41. doi: 10.2337/diacare.27.5.1036

12. Ding EL, Song Y, Malik VS, Liu S. Sex differences of endogenous sex hormones and risk of type 2 diabetes: a systematic review and meta-analysis. JAMA. (2006) 295:1288-99. doi: 10.1001/jama.295.11.1288

13. Oh JY, Barrett-Connor E, Wedick NM, Wingard DL, Rancho Bernardo S. Endogenous sex hormones and the development of type 2 diabetes in older men and women: the Rancho Bernardo study. Diabetes Care. (2002) 25:55-60. doi: 10.2337/diacare.25.1.55

14. Haring $R$, Ittermann $T$, Völzke $H$, Krebs $A$, Zygmunt $M$, Felix $\mathrm{SB}$, et al. Prevalence, incidence and risk factors of testosterone deficiency in a population-based cohort of men: results from the study of health in Pomerania. Aging Male. (2010) 13:247-57. doi: $10.3109 / 13685538.2010 .487553$

15. Rastrelli G, Carter EL, Ahern T, Finn JD, Antonio L, O’Neill TW, et al. Development of and recovery from secondary hypogonadism in aging men: prospective results from the EMAS. J Clin Endocrinol Metab. (2015) 100:3172-82. doi: 10.1210/jc.2015-1571

16. Laaksonen DE, Niskanen L, Punnonen K, Nyyssonen K, Tuomainen TP, Valkonen VP, et al. The metabolic syndrome and smoking in relation to hypogonadism in middle-aged men: a prospective cohort study. J Clin Endocrinol Metab. (2005) 90:712-9. doi: 10.1210/jc. 2004-0970

17. Barrett-Connor E. Lower endogenous androgen levels and dyslipidemia in men with non-insulin-dependent diabetes mellitus. Ann Intern Med. (1992) 117:807-11. doi: 10.7326/0003-4819-117-10-807 
18. Corona G, Monami M, Rastrelli G, Aversa A, Sforza A, Lenzi A, et al. Type 2 diabetes mellitus and testosterone: a meta-analysis study. Int J Androl. (2011) 34:528-40. doi: 10.1111/j.1365-2605.2010.01117.x

19. Dhindsa S, Prabhakar S, Sethi M, Bandyopadhyay A, Chaudhuri A, Dandona P. Frequent occurrence of hypogonadotropic hypogonadism in type 2 diabetes. J Clin Endocrinol Metab. (2004) 89:5462-8. doi: 10.1210/jc.2004-0804

20. Tomar R, Dhindsa S, Chaudhuri A, Mohanty P, Garg R, Dandona P. Contrasting testosterone concentrations in type 1 and type 2 diabetes. Diabetes Care. (2006) 29:1120-2. doi: 10.2337/dc06-0197

21. Corona G, Rastrelli G, Maggi M. Diagnosis and treatment of lateonset hypogonadism: systematic review and meta-analysis of TRT outcomes. Best Pract Res Clin Endocrinol Metab. (2013) 27:557-79. doi: 10.1016/j.beem.2013.05.002

22. Corona G, Rastrelli G, Vignozzi L, Mannucci E, Maggi M. How to recognize late-onset hypogonadism in men with sexual dysfunction. Asian J Androl. (2012) 14:251-9. doi: 10.1038/aja.2011.138

23. Corona G, Vignozzi L, Sforza A, Mannucci E, Maggi M. Obesity and late-onset hypogonadism. Mol Cell Endocrinol. (2015) 418(Pt 2):120-33. doi: 10.1016/j.mce.2015.06.031

24. Lo EM, Rodriguez KM, Pastuszak AW, Khera M. Alternatives to testosterone therapy: a review. Sex Med Rev. (2018) 6:106-13. doi: 10.1016/j.sxmr.2017.09.004

25. Bosman E, Esterhuizen AD, Rodrigues FA, Becker PJ, Hoffmann WA. Effect of metformin therapy and dietary supplements on semen parameters in hyperinsulinaemic males. Andrologia. (2015) 47:974-9. doi: 10.1111 /and.12366

26. Morgante G, Tosti C, Orvieto R, Musacchio MC, Piomboni P, De Leo V. Metformin improves semen characteristics of oligoteratoasthenozoospermic men with metabolic syndrome. Fertil Steril. (2011) 95:2150-2. doi: 10.1016/j.fertnstert.2010.12.009

27. Wang C, Nieschlag E, Swerdloff R, Behre HM, Hellstrom WJ, Gooren LJ, et al. Investigation, treatment and monitoring of late-onset hypogonadismin males: ISA, ISSAM, EAU, EAA and ASA recommendations. Eur J Endocrinol. (2008) 159:507-14. doi: 10.1530/EJE-08-0601

28. Kapoor D, Aldred H, Clark S, Channer KS, Jones TH. Clinical and biochemical assessment of hypogonadism in men with type 2 diabetes: correlations with bioavailable testosterone and visceral adiposity. Diabetes Care. (2007) 30:911-7. doi: 10.2337/dc06-1426

29. Ramirez ME, McMurry MP, Wiebke GA, Felten KJ, Ren K, Meikle AW, et al. Evidence for sex steroid inhibition of lipoprotein lipase in men: comparison of abdominal and femoral adipose tissue. Metabolism. (1997) 46:179-85. doi: 10.1016/S0026-0495(97)90299-7

30. Pitteloud N, Mootha VK, Dwyer AA, Hardin M, Lee H, Eriksson $\mathrm{KF}$, et al. Relationship between testosterone levels, insulin sensitivity, and mitochondrial function in men. Diabetes Care. (2005) 28:1636-42. doi: 10.2337/diacare.28.7.1636

31. Brüning JC, Gautam D, Burks DJ, Gillette J, Schubert M, Orban PC, et al. Role of brain insulin receptor in control of body weight and reproduction. Science. (2000) 289:2122-5. doi: 10.1126/science.289.5487.2122

32. Cohen PG. The hypogonadal-obesity cycle: role of aromatase in modulating the testosterone-estradiol shunt-a major factor in the genesis of morbid obesity. Med Hypotheses. (1999) 52:49-51. doi: 10.1054/mehy.1997.0624

33. Russell SH, Small CJ, Stanley SA, Franks S, Ghatei MA, Bloom SR. The in vitro role of tumor necrosis factor-alpha and interleukin-6 in the hypothalamic-pituitary gonadal axis. J Neuroendocrinol. (2001) 13:296-301. doi: 10.1046/j.1365-2826.2001.00632.x

34. Watanobe H, Hayakawa Y. Hypothalamic interleukin-1 beta and tumor necrosis factor-alpha, but not interleukin-6, mediate the endotoxin induced suppression of the reproductive axis in rats. Endocrinology. (2003) 144:486875. doi: 10.1210/en.2003-0644

35. Isidori AM, Caprio M, Strollo F, Moretti C, Frajese G, Isidori A, et al. Leptin and androgens in male obesity: evidence for leptin contribution to reduced androgen levels. J Clin Endocrinol Metab. (1999) 84:3673-80. doi: 10.1210/jcem.84.10.6082

36. Zhai L, Zhao J, Zhu Y, Liu Q, Niu W, Liu C, et al. Downregulation of leptin receptor and kisspeptin/GPR54 in the murine hypothalamus contributes to male hypogonadism caused by high-fat diet-induced obesity. Endocrine. (2018) 62:195-206. doi: 10.1007/s12020-018-1646-9

37. Glass AR, Swerdloff RS, Bray GA, Dahms WT, Atkinson RL. Low serum testosterone and sex-hormone-binding-globulin in massively obese men. $J$ Clin Endocrinol Metab. (1977) 45:1211-9. doi: 10.1210/jcem-45-6-1211

38. Andersson B, Marin P, Lissner L, Vermeulen A, Bjorntorp P. Testosterone concentrations in women and men with NIDDM. Diabetes Care. (1994) 17:405-11. doi: 10.2337/diacare.17.5.405

39. Simo R, Saez-Lopez C, Barbosa-Desongles A, Hernandez C, Selva DM. Novel insights in SHBG regulation and clinical implications. Trends Endocrinol Metab. (2015) 26:376-83. doi: 10.1016/j.tem.2015.05.001

40. Gyawali P, Martin SA, Heilbronn LK, Vincent AD, Jenkins AJ, Januszewski AS, et al. Cross-sectional and longitudinal determinants of serum sex hormone binding globulin (SHBG) in a cohort of community-dwelling men. PLoS ONE. (2018) 13:e0200078. doi: 10.1371/journal.pone.0200078

41. Saboor Aftab SA, Kumar S, Barber TM. The role of obesity and type 2 diabetes mellitus in the development of male obesity-associated secondary hypogonadism. Clin Endocrinol. (2013) 78:330-7. doi: 10.1111/cen.12092

42. van Dam EW, Dekker JM, Lentjes EG, Romijn FP, Smulders YM, Post WJ, et al. Steroids in adult men with type 1 diabetes: a tendency to hypogonadism. Diabetes Care. (2003) 26:1812-18. doi: 10.2337/diacare.26.6.1812

43. Yialamas MA, Dwyer AA, Hanley E, Lee H, Pitteloud N, Hayes FJ. Acute sex steroid withdrawal reduces insulin sensitivity in healthy men with idiopathic hypogonadotropic hypogonadism. J Clin Endocrinol Metab. (2007) 92:42549. doi: 10.1210/jc.2007-0454

44. Dwyer AA, Quinton R. The metabolic syndrome in central hypogonadotrophic hypogonadism. Front Horm Res. (2018) 49:156-69. doi: $10.1159 / 000485998$

45. Smith JC, Bennett S, Evans LM, Kynaston HG, Parmar M, Mason MD, et al. The effects of induced hypogonadismon arterial stiffness, body composition, and metabolic parameters in males with prostate cancer. J Clin Endocrinol Metab. (2001) 86:4261-7. doi: 10.1210/jc.86.9.4261

46. Smith MR. Treatment-related diabetes and cardiovascular disease in prostate cancer survivors. Ann Oncol. (2008) 19(Suppl. 7):86-90. doi: 10.1093/annonc/mdn458

47. Smith MR, Finkelstein JS, McGovern FJ, Zietman AL, Fallon MA, Schoenfeld $\mathrm{DA}$, et al. Changes in body composition during androgen deprivation therapy for prostate cancer. J Clin Endocrinol Metab. (2002) 87:599-603. doi: 10.1210/jcem.87.2.8299

48. Smith MR, Lee H, Nathan DM. Insulin sensitivity during combined androgen blockade for prostate cancer. J Clin Endocrinol Metab. (2006) 91:1305-8. doi: 10.1210/jc.2005-2507

49. Bosco C, Crawley D, Adolfsson J, Rudman S, Van Hemelrijck M. Quantifying the evidence for the risk of metabolic syndrome and its components following androgen deprivation therapy for prostate cancer: a meta-analysis. PLoS ONE. (2015) 10:e0117344. doi: 10.1371/journal.pone.0117344

50. Keating NL, O'Malley AJ, Freedland SJ, Smith MR. Diabetes and cardiovascular disease during androgen deprivation therapy: observational study of veterans with prostate cancer. J Natl Cancer Inst. (2010) 102:39-46. doi: 10.1093/jnci/djp404

51. Mancini A, Raimondo S, Di Segni C, Gadotti G, Giacchi E, Zollino M, et al. Hypogonadism in metabolic syndrome: cause or consequence? Lesson from genetic hypogonadism and disorders of gender identity. J Endocrinol Diabetes Obes. (2014) 2:1040.

52. Kelly DM, Jones TH. Testosterone and obesity. Obes Rev. (2015) 16:581-606. doi: 10.1111/obr.12282

53. Giagulli VA, Kaufman JM, Vermeulen A. Pathogenesis of the decreased androgen levels in obese men. J Clin Endocrinol Metab. (1994) 79:997-1000. doi: 10.1210/jcem.79.4.7962311

54. Vermeulen A, Kaufman JM, Deslypere JP, Thomas G. Attenuated luteinizing hormone (LH) pulse amplitude but normal LH pulse frequency, and its relation to plasma androgens in hypogonadism of obese men. J Clin Endocrinol Metab. (1993) 76:1140-6. doi: 10.1210/jcem.76.5.8496304

55. Isidori AM, Giannetta E, Greco EA, Gianfrilli D, Bonifacio V, Isidori A, et al. Effects of testosterone on body composition, bone metabolism and serum lipid profile in middle-aged men: a meta-analysis. Clin Endocrinol (Oxf). (2005) 63:280-93. doi: 10.1111/j.1365-2265.2005.02339.x 
56. Couillard C, Gagnon J, Bergeron J, Leon AS, Rao DC, Skinner JS, et al. Contribution of body fatness and adipose tissue distribution to the age variation in plasma steroid hormone concentrations in men: the HERITAGE Family. Study J Clin Endocrinol Metab. (2000) 85:1026-31. doi: $10.1210 /$ jcem.85.3.6427

57. Seidell JC, Bjorntorp P, Sjostrom L, Kvist H, Sannerstedt R. Visceral fat accumulation in men is positively associated with insulin, glucose, and C peptide levels, but negatively with testosterone levels. Metabolism. (1990) 39:897-901. doi: 10.1016/0026-0495(90)90297-P

58. Katznelson L, Rosenthal DI, Rosol MS, Anderson EJ, Hayden DL, Schoenfeld DA, et al. Using quantitative CT to assess adipose distribution in adult men with acquired hypogonadism. Am J Roentgenol. (1998) 170:423-7. doi: 10.2214/ajr.170.2.9456958

59. Haffner SM, Valdez RA, Mykkanen L, Stern MP, Katz MS. Decreased testosterone and dehydroepiandrosterone sulfate concentrations are associated with increased insulin and glucose concentrations in nondiabetic men. Metabolism. (1994) 43:599-603. doi: 10.1016/0026-0495(94) 90202-X

60. Phillips GB. Relationship between serum sex hormones and the glucoseinsulin-lipid defect in men with obesity. Metabolism. (1993) 42:116-20. doi: 10.1016/0026-0495(93)90181-M

61. Simon D, Preziosi P, Barrett-Connor E, Roger M, Saint-Paul M, Nahoul $\mathrm{K}$, et al. Interrelation between plasma testosterone and plasma insulin in healthy adult men: the Telecom Study. Diabetologia. (1992) 35:173-7. doi: 10.1007/BF00402551

62. Kaplan SA, Meehan AG, Shah A. The age related decrease in testosterone is significantly exacerbated in obese men with the metabolic syndrome. What are the implications for the relatively high incidence of erectile dysfunction observed in these men? J Urol. (2006) 176:1524-7; discussion 1527-8. doi: 10.1016/j.juro.2006.06.003

63. Zumoff B, Strain GW, Miller LK, Rosner W, Senie R, Seres DS, et al. Plasma free and non-sex-hormone-binding-globulin-bound testosterone are decreased in obese men in proportion to their degree of obesity. J Clin Endocrinol Metab. (1990) 71:929-31. doi: 10.1210/jcem-71-4-929

64. Haffner SM, Karhapaa P, Mykkanen L, Laakso M. Insulin resistance, body fat distribution, and sex hormones in men. Diabetes. (1994) 43:212-9. doi: 10.2337/diabetes.43.2.212

65. Daubresse JC, Meunier JC, Wilmotte J, Luyckx AS, Lefebvre PJ. Pituitary testicular axis in diabetic men with and without sexual impotence. Diabetes Metab. (1978) 4:233-7.

66. Grossmann M, Thomas MC, Panagiotopoulos S, Sharpe K, Macisaac RJ, Clarke S, et al. Low testosterone levels are common and associated with insulin resistance in men with diabetes. J Clin Endocrinol Metab. (2008) 93:1834-40. doi: 10.1210/jc.2007-2177

67. Corona G, Mannucci E, Forti G, Maggi M. Following the common association between testosterone deficiency and diabetes mellitus, can testosterone be regarded as a new therapy for diabetes? Int J Androl. (2009) 32:431-41. doi: 10.1111/j.1365-2605.2009.00965.x

68. Tripathy D, Dhindsa S, Garg R, Khaishagi A, Syed T, Dandona P. Hypogonadotropic hypogonadism in erectile dysfunction associated with type 2 diabetes mellitus: a common defect? Metab Syndr Relat Disord. (2003) 1:75-80. doi: 10.1089/154041903321648270

69. Mulligan T, Frick MF, Zuraw QC, Stemhagen A, McWhirter C. Prevalence of hypogonadism in males aged at least 45 years: the HIM study. Int J Clin Pract. (2006) 60:762-9. doi: 10.1111/j.1742-1241.2006. 00992.x

70. Laaksonen DE, Niskanen L, Punnonen K, Nyyssönen K, Tuomainen TP, Salonen R, et al. Sex hormones, inflammation and the metabolic syndrome: a population-based study. Eur J Endocrinol. (2003) 149:601-8. doi: 10.1530/eje.0.1490601

71. Tsai EC, Matsumoto AM, Fujimoto WY, Boyko EJ. Association of bioavailable, free, and total testosterone with insulin resistance: influence of sex hormone-binding globulin and body fat. Diabetes Care. (2004) 27:861-8. doi: 10.2337/diacare.27.4.861

72. Agledahl I, Hansen JB, Svartberg J. Impact of testosterone treatment on postprandial triglyceride metabolism in elderly men with subnormal testosterone levels. Scand J Clin Lab Invest. (2008) 68:641-8. doi: 10.1080/00365510801999068
73. Marin P, Krotkiewski M, Bjorntorp P. Androgen treatment of middle-aged, obese men: effects on metabolism, muscle and adipose tissues. Eur J Med. (1992) 1:329-36.

74. Marin P, Oden B, Bjorntorp P. Assimilation and mobilization of triglycerides in subcutaneous abdominal and femoral adipose tissue in vivo in men: effects of androgens. J Clin Endocrinol Metab. (1995) 80:239-43. doi: $10.1210 /$ jc. 80.1 .239

75. Saad F, Gooren L, Haider A, Yassin A. An exploratory study of the effects of 12 month administration of the novel long-acting testosterone undecanoate on measures of sexual function and the metabolic syndrome. Arch Androl. (2007) 53:353-7. doi: 10.1080/01485010701730880

76. Mårin P, Holmäng S, Jönsson L, Sjöström L, Kvist H, Holm G, et al. The effects of testosterone treatment on body composition and metabolism in middle-aged obese men. Int J Obes Relat Metab Disord. (1992) 16:991-7.

77. Cai X, Tian Y, Wu T, Cao CX, Li H, Wang KJ. Metabolic effects of testosterone replacement therapy on hypogonadal men with type 2 diabetes mellitus: a systematic review and meta-analysis of randomized controlled trials. Asian J Androl. (2014) 16:146-52. doi: 10.4103/1008-682X.122346

78. Saad F, Gooren LJ, Haider A, Yassin A. A dose-response study of testosterone on sexual dysfunction and features of the metabolic syndrome using testosterone gel and parenteral testosterone undecanoate. J Androl. (2008) 29:102-5. doi: 10.2164/jandrol.107.002774

79. Heufelder AE, Saad F, Bunck MC, Gooren L. Fifty-two-week treatment with diet and exercise plus transdermal testosterone reverses the metabolic syndrome and improves glycemic control in men with newly diagnosed type 2 diabetes and subnormal plasma testosterone. J Androl. (2009) 30:726-33. doi: 10.2164/jandrol.108.007005

80. Kalinchenko SY, Tishova YA, Mskhalaya GJ, Gooren LJ, Giltay EJ, Saad F. Effects of testosterone supplementation on markers of the metabolic syndrome and inflammation in hypogonadal men with the metabolic syndrome: the double-blinded placebo-controlled Moscow study. Clin Endocrinol (Oxf). (2010) 73:602-12. doi: 10.1111/j.1365-2265.2010.03845.x

81. Bhasin S, Storer TW, Berman N, Yarasheski KE, Clevenger B, Phillips $\mathrm{J}$, et al. Testosterone replacement increases fat-free mass and muscle size in hypogonadal men. J Clin Endocrinol Metab. (1997) 82:407-13. doi: $10.1210 /$ jc.82.2.407

82. Snyder PJ, Peachey H, Berlin JA, Hannoush P, Haddad G, Dlewati A, et al. Effects of testosterone replacement in hypogonadal men. J Clin Endocrinol Metab. (2000) 85:2670-7. doi: 10.1210/jc.85.8.2670

83. Wang C, Eyre DR, Clark R, Kleinberg D, Newman C, Iranmanesh A, et al. Sublingual testosterone replacement improves muscle mass and strength, decreases bone resorption, and increases bone formation markers in hypogonadal men-a clinical research center study. J Clin Endocrinol Metab. (1996) 81:3654-62. doi: 10.1210/jcem.81.10.8855818

84. Lovejoy JC, Bray GA, Greeson CS, Klemperer M, Morris J, Partington C, et al. Oral anabolic steroid treatment, but not parenteral androgen treatment, decreases abdominal fat in obese, older men. Int J Obes Relat Metab Disord. (1995) 19:614-24.

85. Svartberg J, Agledahl I, Figenschau Y, Sildnes T, Waterloo K, Jorde R. Testosterone treatment in elderly men with subnormal testosterone levels improves body composition and BMD in the hip. Int J Impot Res. (2008) 20:378-87. doi: 10.1038/ijir.2008.19

86. Münzer T, Harman SM, Hees P, Shapiro E, Christmas C, BellantoniMF, et al. Effects of GH and/or sex steroid administration on abdominal subcutaneous and visceral fat in healthy aged women and men. J Clin Endocrinol Metab. (2001) 86:3604-10. doi: 10.1210/jcem.86.8.7773

87. Woodhouse LJ, Gupta N, Bhasin M, Singh AB, Ross R, Phillips J, et al. Dose-dependent effects of testosterone on regional adipose tissue distribution in healthy young men. J Clin Endocrinol Metab. (2004) 89:71826. doi: 10.1210/jc.2003-031492

88. Allan CA, Strauss BJ, Burger HG, Forbes EA, McLachlan RI. Testosterone therapy prevents gain in visceral adipose tissue and loss of skeletal muscle in nonobese aging men. J Clin Endocrinol Metab. (2008) 93:139-46. doi: 10.1210/jc.2007-1291

89. Katznelson L, Finkelstein JS, Schoenfeld DA, Rosenthal DI, Anderson EJ, Klibanski A. Increase in bone density and lean body mass during testosterone administration in men with acquired hypogonadism. J Clin Endocrinol Metab. (1996) 81:4358-65. doi: 10.1210/jcem.81.12.8954042 
90. Snyder PJ, Peachey H, Hannoush P, Berlin JA, Loh L, Lenrow DA, et al. Effect of testosterone treatment on body composition and muscle strength in men over 65 years of age. J Clin Endocrinol Metab. (1999) 84:2647-53. doi: $10.1210 /$ jc.84.8.2647

91. Schroeder ET, Singh A, Bhasin S, Storer TW, Azen C, Davidson T, et al. Effects of an oral androgen on muscle and metabolism in older, community-dwelling men. Am J Physiol Endocrinol Metab. (2003) 284:E1208. doi: 10.1152/ajpendo.00363.2002

92. Schroeder ET, Zheng L, Ong MD, Martinez C, Flores C, Stewart Y, et al. Effects of androgen therapy on adipose tissue and metabolism in older men. J Clin Endocrinol Metab. (2004) 89:4863-72. doi: 10.1210/jc.2004-0784

93. Ghanim H, Dhindsa S, Abuaysheh S, Batra M, Kuhadiya ND, Makdissi A, et al. Diminished androgen and estrogen receptors and aromatase levels in hypogonadal diabetic men: reversal with testosterone. Eur J Endocrinol. (2018) 178:277-83. doi: 10.1530/EJE-17-0673

94. Simon D, Charles MA, Lahlou N, Nahoul K, Oppert JM, Gouault-Heilmann $\mathrm{M}$, et al. Androgen therapy improves insulin sensitivity and decreases leptin level in healthy adult men with low plasma total testosterone: a 3-month randomized placebo-controlled trial. Diabetes Care. (2001) 24:2149-51. doi: 10.2337/diacare.24.12.2149

95. Kapoor D, Goodwin E, Channer KS, Jones TH. Testosterone replacement therapy improves insulin resistance, glycaemic control, visceral adiposity and hypercholesterolaemia in hypogonadal men with type 2 diabetes. Eur J Endocrinol. (2006) 154:899-906. doi: 10.1530/eje.1. 02166

96. Dhindsa S, Ghanim H, Batra M, Kuhadiya ND, Abuaysheh S, Sandhu S, et al. Insulin resistance and inflammation in hypogonadotropic hypogonadism and their reduction after testosterone replacement in men with type 2 . Diabetes Diabetes Care. (2016) 39:82-91. doi: 10.2337/dc15-1518

97. Friedl KE, Jones RE, Hannan CJ Jr, Plymate SR. The administration of pharmacological doses of testosterone or 19-nortestosterone to normal men is not associated with increased insulin secretion or impaired glucose tolerance. J Clin Endocrinol Metab. (1989) 68:971-5. doi: 10.1210/jcem-68-5-971

98. Huang G, Pencina KM, Li Z, Basaria S, Bhasin S, Travison TG, et al. Long-term testosterone administration on insulin sensitivity in older men with low or low-normal testosterone levels. J Clin Endocrinol Metab. (2018) 103:1678-85. doi: 10.1210/jc.2017-02545

99. Corrales JJ, Burgo RM, Garca-Berrocal B, Almeida M, Alberca I, GonzálezBuitrago JM, et al. Partial androgen deficiency in aging type 2 diabeticmen and its relationship to glycemic control. Metabolism. (2004) 53:666-72. doi: 10.1016/j.metabol.2003.12.016

100. Tripathy D, Shah P, Lakshmy R, Reddy KS. Effect of testosterone replacement on whole body glucose utilization and other cardiovascular risk factors in males with idiopathic hypogonadotrophic hypogonadism. Horm Metab Res. (1998) 30:642-5. doi: 10.1055/s-2007-978950

101. Corona G, Rastrelli G, Monami M, Saad F, Luconi M, Lucchese M, et al. Body weight loss reverts obesity-associated hypogonadotropic hypogonadism: a systematic review and meta-analysis. Eur J Endocrinol. (2013) 168:829-43. doi: 10.1530/EJE-12-0955

102. Casulari LA, Caldas AD, Domingues Casulari Motta L, Lofrano-Porto A. Effects of metformin and short-term lifestyle modification on the improvement of male hypogonadism associated with metabolic syndrome. Minerva Endocrinol. (2010) 35:145-51.

103. Kapoor D, Channer KS, Jones TH. Rosiglitazone increases bioactive testosterone and reduces waist circumference in hypogonadal men with type 2 diabetes. Diab Vasc Dis Res. (2008) 5:135-7. doi: 10.3132/dvdr.2008.022

104. Shao N, Yu XY, Yu YM, Li BW, Pan J, Wu WH, et al. Short-term combined treatment with exenatide and metformin is superior to glimepiride combined metformin in improvement of serum testosterone levels in type 2 diabetic patients with obesity. Andrologia. (2018) 50:e13039. doi: 10.1111/and.13039

105. Jensterle M, Podbregar A, Goricar K, Gregoric N, Janez A. Effects of liraglutide on obesity-associated functional hypogonadism in men. Endocr Connect. (2019) 8:195-202. doi: 10.1530/EC-18-0514

106. Giagulli VA, Carbone MD, Ramunni MI, Licchelli B, De Pergola G, Sabbà C, et al. Adding liraglutide to lifestyle changes, metformin and testosterone therapy boosts erectile function in diabetic obese men with overt hypogonadism. Andrology. (2015) 3:1094-103. doi: 10.1111/andr.12099

Conflict of Interest Statement: The authors declare that the research was conducted in the absence of any commercial or financial relationships that could be construed as a potential conflict of interest.

Copyright (C) 2019 Pivonello, Menafra, Riccio, Garifalos, Mazzella, de Angelis and Colao. This is an open-access article distributed under the terms of the Creative Commons Attribution License (CC BY). The use, distribution or reproduction in other forums is permitted, provided the original author(s) and the copyright owner(s) are credited and that the original publication in this journal is cited, in accordance with accepted academic practice. No use, distribution or reproduction is permitted which does not comply with these terms. 